\title{
キャピラリーガスクロマトグラフィーによるポリ塩化 ビフェニルの定量方法
}

\author{
堀本能之*，西 末雄 ${ }^{\circledR}$ ，山口憲治，小口りみ子**
}

(1991 年 7 月 9 日受理)

全ポリ塭化ビフェニルをキャピラリー GC で分離した場合の定量方法を検討した。標準液はカネク ロール $(\mathrm{KC})-300 ， 400 ， 500 ， 600$ の等量をへキサンに溶解し調製した。標準液での各同族体の百分率 $(\mathrm{CB} \%)$ を求める日的で, 原子発光検出器付きキャピラリー GC により炭素及び塩素の発光をモ二タ したクロマトグラムを得た。炭素によるクロマトグラムから各同族体のビフェニル基の百分率, 塩素に よるクロマトグラムの解析からは各同族体の塩素置換数が推定できた。これらの情報を組み合わせ分離 した 101 のピークの $90 \%$ について CB％が得られた。CB％の精度検証のため数種の単一成分標準物 質を用いて分析した結果，一十分な信頼性が証明された。 CB％を利用した定量値計算方法を述べた。

\section{1 緒訔}

睘境試料中のポリ塩化ビフェニル (PCB) の分析方法 に関する国内模準分析法では, 充てん力ラムガスクロマ トグラフィーが採用されてきだ。すなおち丁.業用 PCB の一定組成の混合物 仂ネクロール (KG) - $300,-400$, -500 及びー600 の等望混会物\}を標準 PCB とし，クロ マトグラフの条件を規定して测定を行う，得られたクロ マトグラムの齐ピーク售さを㮠準 PCBの場合と比較し 分量する。この際，噤準PCBの齐ピークにはピークの 含有垶 $\{\mathrm{CB}(\%)\}$ があらかじめ测定され，規定されて おり，分量の根挑となっている。

しかし上梳標準 PCB を構成する PCB 同族体の数は 100 を超えるにもかかわらず，充てん力ラムで分離され たピークの数が 26〜29であることから，多くの成分が ピーク内で重複していることは明しである. 塩素置換度 の異なるものが同一ピーク内に混在することも否定でき ず, その場合は電子捕獲検出器（ECD）による定量が 複雑よなる。

一方, 環境試料中の PCB の濃度が低減しつつあり, より微少量の分析が求められる最近では, 分離効率の高 いカラムを用いピークの感度を高めることが必要であ る. 又, 最近では PCB の成分ごとの毒性に注目し, 特

* 化学技術研究所: 305 茨城県つくば市東 1-1

** 横河電機 (株): 180 武蔵野甫中町 2-11-19 三鷹ビ ル
定の $\mathrm{PCB}$ 同族体 (Co-planer $\mathrm{PCB})$ を重点的に测定す る考え方もある.

この様な背景から PCB の分析にキャピラリーカラム ガスクロマトグラフィー (キャピラリー GC) の使用が 必要亡なり研究も行われている2) - 8). この場合, 定量 方法が問題であるが，個々の化合物ごとに標準物質を用 意し定量する方法は，コストの面で現実的ではない。こ れに対して工業用 PCB を標準 PCB とする従来の考え 方は現実的である。その場合キャピラリー GC で分離 した個々の成分の $\mathrm{CB}(\%)$ を正確に求める必要があ る.

この報告はキャピラリー GC による PCB の定量に必 要な標準液の組成及びそれに用いる分析法について検討 した結果をとりまとめたものである.

\section{2 実験}

\section{2・1 PCB 標準液の調製}

$\mathrm{KC}-300,400,500$, 及び 600 の等量（各 $10 \mathrm{mg}$ ）を 容量 $10 \mathrm{ml}$ のメスフラスコ中にとり，へキサンを加え て溶解し定容とした。これをへキサンで希釈して目的の 濃度 $(80 \mathrm{mg} / \mathrm{l})$ の溶液を調製した.

\section{$2 \cdot 2$ 分析方法}

\section{$2 \cdot 2 \cdot 1$ 標準液中の塩化ビフェニル組成の分析}

キャピラリーGG によって分離した各成分の炭素及 び塩素の元素組成を求める目的で, 原子発光検出器を用 
いるガスクロマトグラフィー（GC-AED）を行った. 測定条件は Table 1 に示した.

Table 1 Operation conditions for GC-AED

\begin{tabular}{ll}
\hline Instrumentation & $\begin{array}{l}\text { HP 9521A GC AED (Hew- } \\
\text { lett Packard) } \\
\text { DB-1 } 60 \mathrm{~m} \text { length, } 0.25 \mathrm{~mm}\end{array}$ \\
Column & $\begin{array}{l}\text { i.d., } 0.25 \mu \mathrm{m} \text { film } \\
\text { splitless mode (purge on } \\
\text { time } 1.5 \mathrm{~min})\end{array}$ \\
Sample injection mode & $1 \mu \mathrm{l}$ \\
Sample injected & $270^{\circ} \mathrm{C}$ \\
Injection temperature & Initial $60^{\circ} \mathrm{C}(1.5 \mathrm{~min})$, \\
Column oven temperature & Rate $20^{\circ} \mathrm{C} / \mathrm{min} \mathrm{to} 150^{\circ} \mathrm{C}$, \\
& $2^{\circ} \mathrm{C} / \mathrm{min}$ to $300^{\circ} \mathrm{C}$ \\
& $3.5 \sim 6.5 \mathrm{~min}$ \\
Solvent dump & $495.7 \mathrm{~nm}$ \\
Monitor wavelength for carbon & for chlorine $479.5 \mathrm{~nm}$ \\
& helium $30 \mathrm{ml} / \mathrm{min}$ \\
Make up gas & oxygen \\
Reagent gas &
\end{tabular}

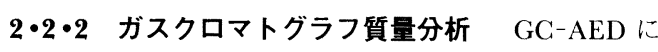
よる置換塩素数の測定結果の確認の目的で同じ PCB 試 料を $\mathrm{GC} / \mathrm{MS}$ によって分析した．分析条件は次の之お りである. 装置: HP5970 (Hewlett Packard); GC の条 件: Table 1 と同じ; 測定: 走査モード.

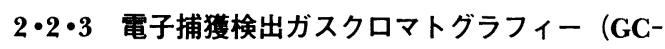
ECD 装置: GC, HP5890 (Hewlett Packard); 検出 器: G-1880 柳本製作所; GC の条件: Table 1 之同じ.

3 結果及び考察

\section{$3 \cdot 1$ ビフェニル基量存在比の測定}

$\mathrm{PCB}$ 同族体の化学構造の特徴は, ビフェニル基が共 通であり，他に炭素原子が存在しないことである。従つ て GC-AED における炭素の発光から得られたクロマト グラム (Fig. 1) の各ピーク高さの比は, 各同族体のビ フェニル基の存在比を表すものと考えられる. 又 GC-AED における炭素応答のダイナミックレンジは $2 \times 10^{4}$, 最小検出量 $15 \mathrm{pg} / \mathrm{s}$ とカタログ表示されてい

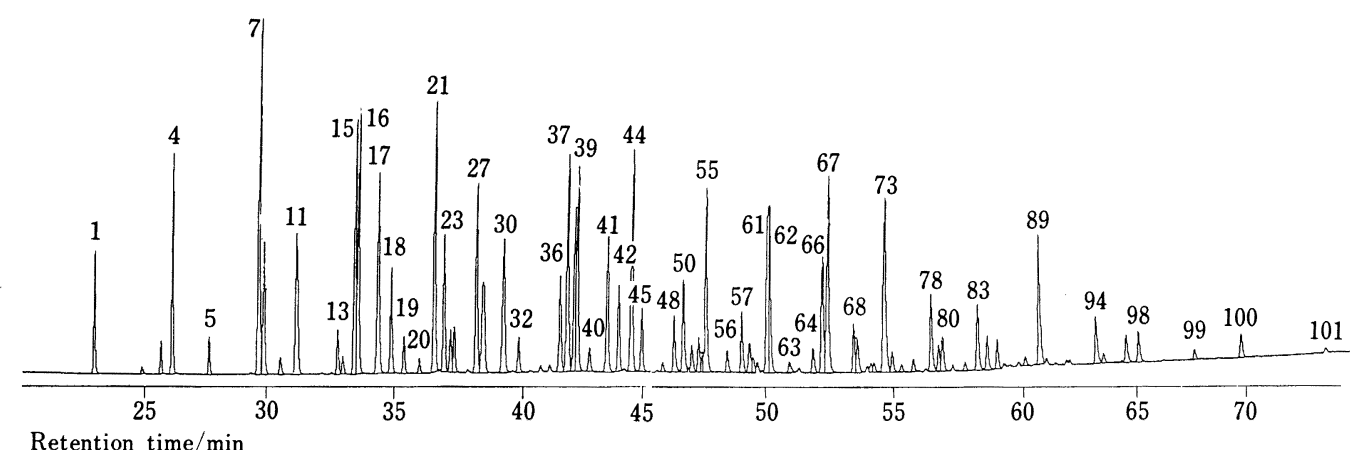

Retention time/min

Fig. 1 Gas chromatogram of PCB standard mixture monitored by. AED carbon emission (495.7 nm) Total PCB concentration: $80 \mathrm{mg} \mathrm{l}^{-1}$

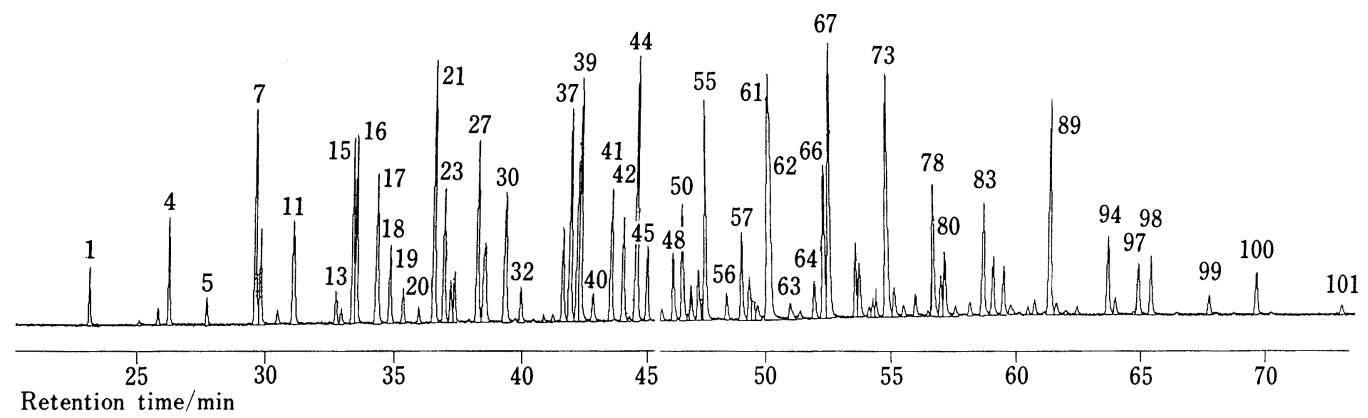

Fig. 2 Gas chromatogram of PCB standard mixture monitored by AED chlorine emission (479.5 $\mathrm{nm}$ ) Total PCB concentration: $80 \mathrm{mg} \mathrm{l}^{-1}$ 
る.この実験では濃度 $80 \mathrm{mg} / 1$ の PGB 標準液の $1 \mu \mathrm{l}$ $\mathrm{GC}$ 力ラムに注人しており, 分離された最大の成分でも その量は $5 \mathrm{ng}$ 以下である. 従って測定はすべてダイナ ミックレンジ内で行ったことになり，クロマトグラムの ピーク高さ值はビフェニル基の量に比例すると思われ る.

\section{$3 \cdot 2$ 置換塩素数の推定}

炭素及び塩素の発光の同時モニターによって得られた ガスクロマトグラム（Fig. 1 及び Fig. 2) から, 各ピー クごとに炭素と填素のピーク高さ比 $(\mathrm{Cl} / \mathrm{C})$ を求め, それから置換塩素数が推定できる. そのためには置換塩 素数既知の基準物質を用い, $\mathrm{Cl} / \mathrm{C}$ 值と置換塩素数との 関係を求める必要がある. 塩素化ビフェニル純品 $\left(2,2^{\prime}, 5^{\prime}, 5^{\prime}\right.$-テトラクロロビフェニル) を Table 1 記載と 同様な条件でガスクロマトグラフィーを行ったところ， Fig. 1 の No. 21 ピークと保持時間が合致した.このこ とからピーク No. 21 は塩素置換数が 4 のクロロビフェ ニルと推定した。他のピーク成分の置換塩素数は下記の 式から計算した。

\section{各ピーク成分の置換塩素数 $=(\mathrm{Cl} / \mathrm{C}) / 0.417 \times 4$}

ここで $\mathrm{Cl}$ : 塩素モニターで得たピーク高さ; $\mathrm{C}$ : 炭素モ ニターで得たピーク高さ; 0.417: 本実験でのピーク No. 21 における Cl/C 值; 4: ピーク No. 21 の置換塩素数で ある。

PCB 標準液を Table 1 の測定条件で GC/MS（走査 モード)により分析し, 各ピークごとに質量スペクトル

Table 2 List of percent abundances $(\mathrm{CB} \%)$ of individual congener with retention index (RI) and chlorine substituted number (CL)

\begin{tabular}{|c|c|c|c|c|c|c|c|c|c|c|c|}
\hline Peak No. & $\mathrm{CB} \%$ & RI & CL & Peak No. & $\mathrm{CB} \%$ & RI & CL & Peak No. & $\mathrm{CB} \%$ & RI & CL \\
\hline 1 & 1.40 & 1596 & 2 & 38 & 2.40 & 2030 & 4 & 71 & 0.19 & 2299 & 6 \\
\hline 2 & 0.08 & 1641 & 2 & 39 & 3.45 & 2032 & 5 & 72 & 0.21 & 2302 & 7 \\
\hline 3 & 0.38 & 1658 & 2 & 40 & 0.39 & 2043 & 5 & 73 & 3.17 & 2312 & 6 \\
\hline 4 & 2.54 & 1669 & 2 & 41 & 2.01 & 2059 & 4 & 74 & 0.38 & 2319 & 6 \\
\hline 5 & 0.49 & 1703 & 3 & 42 & 1.43 & 2070 & 5 & 75 & 0.15 & 2327 & 6 \\
\hline 7 & 4.78 & 1750 & 3 & 43 & 0.06 & 2075 & 5 & 76 & 0.28 & 2339 & 7 \\
\hline 9 & 1.75 & 1755 & 3 & 44 & 3.70 & 2083 & 5 & 78 & 1.57 & 2356 & 7 \\
\hline 11 & 1.87 & 1785 & 3 & 45 & 1.05 & 2092 & 5 & 79 & 0.49 & 2361 & 6 \\
\hline 13 & 0.57 & 1823 & 3 & 47 & 0.17 & 2110 & 5 & 80 & 0.74 & 2366 & 7 \\
\hline 14 & 0.23 & 1826 & 3 & 48 & 0.91 & 2121 & 5 & 81 & 0.12 & 2375 & 6 \\
\hline 16 & 3.52 & 1841 & 3 & 50 & 1.59 & 2130 & 5 & $82^{\dagger}$ & 0.19 & 2387 & 7 \\
\hline $17^{+}$ & 2.66 & 1858 & 3 & $52^{\dagger}$ & 0.46 & 2137 & 5 & 83 & 1.33 & 2399 & 7 \\
\hline 18 & 1.56 & 1869 & 4 & 53 & 0.64 & 2144 & 6 & 84 & 0.70 & 2408 & 7 \\
\hline 19 & 0.54 & 1880 & 4 & 55 & 3.04 & 2151 & 5 & 85 & 0.62 & 2418 & 7 \\
\hline 20 & 0.23 & 1894 & 4 & 56 & 0.37 & 2168 & 5 & 86 & 0.12 & 2425 & 8 \\
\hline $21^{\dagger}$ & 4.09 & 1908 & 4 & 57 & 1.10 & 2182 & 6 & 87 & 0.09 & 2440 & 8 \\
\hline 23 & 2.06 & 1916 & 4 & 58 & 0.51 & 2189 & 6 & 88 & 0.19 & 2447 & 7 \\
\hline 24 & 0.63 & 1921 & 4 & 59 & 0.28 & 2192 & 6 & 89 & 2.61 & 2461 & 7 \\
\hline 25 & 0.80 & 1925 & 4 & 60 & 0.19 & 2195 & 6 & 90 & 0.13 & 2467 & 7 \\
\hline 26 & 0.05 & 1936 & 3 & 61 & 3.21 & 2206 & 6 & 92 & 0.09 & 2485 & 8 \\
\hline 27 & 2.81 & 1944 & 4 & 62 & 3.01 & 2207 & 6 & 93 & 0.09 & 2498 & 8 \\
\hline 28 & 0.39 & 1949 & 3 & 63 & 0.20 & 2224 & 6 & 94 & 0.94 & 2515 & 7 \\
\hline 29 & 0.89 & 1950 & 4 & 64 & 0.09 & 2234 & 6 & 95 & 0.20 & 2522 & 7 \\
\hline 30 & 1.98 & 1967 & 4 & 65 & 0.47 & 2247 & 6 & 97 & 0.59 & 2547 & 8 \\
\hline 32 & 0.53 & 1977 & 4 & 66 & 1.91 & 2255 & 5 & 98 & 0.67 & 2560 & 8 \\
\hline 34 & 0.09 & 1999 & 4 & $67^{\dagger}$ & 3.59 & 2261 & 6 & 99 & 0.22 & 2618 & 8 \\
\hline 35 & 0.10 & 2007 & 4 & 68 & 0.90 & 2284 & 6 & $100^{\dagger}$ & 0.50 & 2662 & 8 \\
\hline 36 & 1.42 & 2016 & 4 & 69 & 0.67 & 2287 & 7 & $101^{\dagger}$ & 0.11 & 2752 & 9 \\
\hline 37 & 3.30 & 2024 & 4 & 70 & 0.13 & 2296 & 6 & & & & \\
\hline
\end{tabular}

Peaks identified: (17) 2,3,4-trichlorobiphenyl; (21) 2,2',5,5'-tetrachlorobiphenyl ; (52) 2,3,4,5,6-pentachloro-

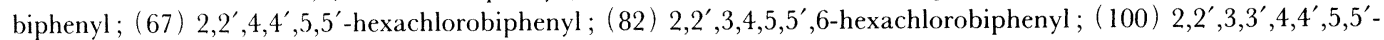

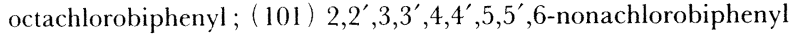




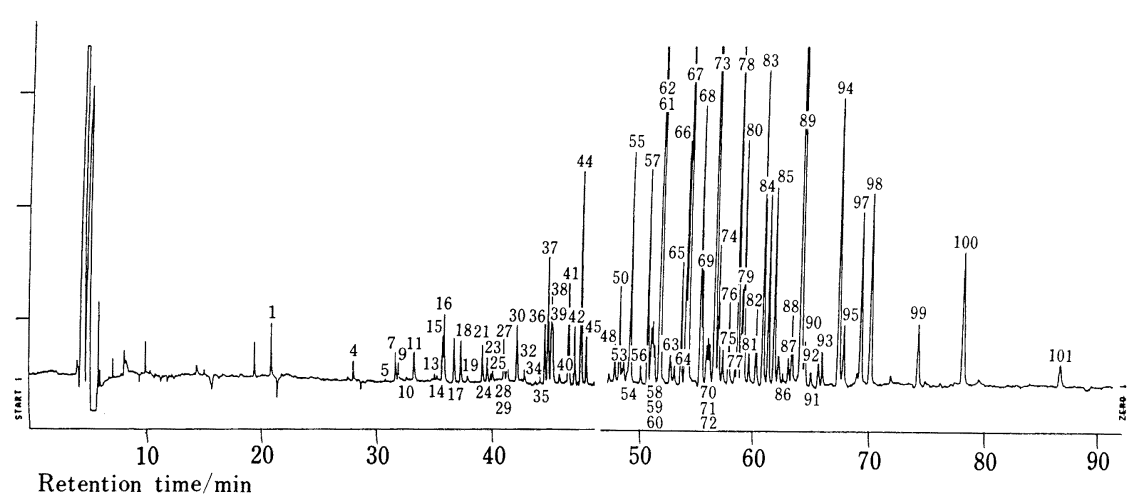

Fig. 3 Gas chromatogram of PCB standard mixture monitored by electron capture detector Total PCB concentration: $1 \mathrm{mg} / \mathrm{l}$

を得,これらから置換塩素数を推定した。ほとんどの ピークにおいて GC-AED による置換塩素数の測定結果 と合致したが, ピーク高さの小さい数個のピークでは GG-AED での塩素の感度不足のため測定精度が不十分 であったので，これらの場合は GC/MS の結果を採用 した (例えばピーク No. 2 及び 26). 各ピークの置換塩 素数は Table 2 に示した.

\section{3•3 CB（\%）の決定}

各ピークごとに，測定されたビフェニル基の量と置換 塩素数とから塩化ビフェニルとしての量を計算し，これ らを総和して, 各塩化ビフェニルの百分率として Table 2 に示した. ただしピークの高さが $0.04 \%$ 以下の成分 についてはデータを棄却した。

決定した $\mathrm{CB} \%$ 值の精度を調べる目的で 5 種類の塩 素化ビフェニル純品の既知量を, Table 1 のクロマトグ ラフ条件下の GG-ECD で測定し，各成分の保持時間及 びピーク高さを求めた. 同じ条件で測定した PCB 標準 液のクロマトグラム（Fig. 3）の中で, 純品と保持時間 が合致したピークについて，CB（\%) から算出した ピーク高さ值と, 純品のピーク高さ值で検量した值を比 較し, 結果を Table 3 に示した. Table 3 の結果は両者 がよく一致し, CB（\%) 值が高い精度を持つことを示 している.

\section{$3 \cdot 4$ 模擬試料中の PCB 濃度の計算}

環境試料の分析では，抽出，抽出物の精製，濃縮など の前処理を経て分析用試料液を調製する。分析は試料液 と PCB 標準液をそれぞれ同一ガスクロマトグラフィー 条件で分析し次式によって計算する.
Table 3 Confirmation of accuracy of $\mathrm{CB} \%$

\begin{tabular}{rcc}
\hline $\begin{array}{c}\text { Peak } \\
\text { No. }\end{array}$ & $\begin{array}{c}\text { Calculated value } \\
\text { based on CB } \%^{\text {a) }} / \\
\mu \mathrm{g} \mathrm{ml}^{-1}\end{array}$ & $\begin{array}{c}\text { Analyzed value } \\
\mu \mathrm{ml}^{-1}\end{array}$ \\
\hline 17 & 0.10 & 0.11 \\
21 & 1.01 & 1.03 \\
67 & 0.011 & 0.011 \\
82 & 0.010 & 0.010 \\
101 & 0.055 & 0.052 \\
\hline
\end{tabular}

a) one $\mu \mathrm{l}$ of standard mixture $(8.7 \mu \mathrm{g} / \mathrm{ml})$ was injected. b) calibrated by pure standard solutions

$$
\begin{aligned}
\text { 試料定量值 }= & {\left.\left[\sum_{X=1}^{101}\left\{h_{X} / H_{X}\right) \times \mathrm{CB} \%_{X}\right\}\right] } \\
& \times \text { 噤準液の濃度 }
\end{aligned}
$$

ただし $H_{X}=\mathrm{PCB}$ 標準液のピーク No. $X$ のピーク高 さ, $h_{X}=$ 試料のピークのうち標準液ピーク No. $X$ と保 持值が合致するピークの高さである.

通常，実試料の分析では GC-ECD が使用される。 の場合の GC の条件はできるだけ本実験の GC-AED の 条件に合致させるべきで, それによってクロマトグラム の各ピークの番号の判別が容易となる. しかし, GC-ECD の装置条件によって, Fig. 1 又はFig. 2 の保 持時間と合致しない場合でも, ピークパターンの判別, 又は保持指標 (Table 2) の利用によってピーク番号が 決定できる.

上記の計算方法の精度を検証する日的で, KC-300 か ら 600 までの混合比を変えて PCB 試験液を調製し, こ れらを Table 1 に示した測定条件下で検出器に ECDを 用い分離と定量を行った。 
Table 4 Recovery test from artificially mixed samples

\begin{tabular}{ccc}
\hline $\begin{array}{c}\text { Test } \\
\text { solution }\end{array}$ & $\begin{array}{c}\text { Prepared } \\
\text { concentration/ } \\
\mu \mathrm{g} \mathrm{l^{-1 }}\end{array}$ & $\begin{array}{c}\text { Measured } \\
\text { concentration/ } \\
\mu \mathrm{I} \mathrm{I}^{-1}\end{array}$ \\
\hline $\mathrm{A}$ & 0.84 & 0.79 \\
$\mathrm{~B}$ & 1.06 & 0.95 \\
\hline
\end{tabular}

すなわちカネクロールの混合比が珙なる (A) $\mathrm{KC}-300: 400: 500: 600=2: 1: 1: 1$, 及 び (B) $\mathrm{KC}-300: 600=1: 1$ の試験液（溶媒へキサン）を調製 し，各ピーク番号及びピーク高さの情報を計算式( 1 )に より計算した結果を Table 4 に示した.

試験液 B で計算濃度がやや低いのは, 一部のピーク の高さが ECDの㨁線領域を超えたためと思われる。そ のような点を考慮すれば Table 4 の結果は計算式( 1 ) の妥当性を示すものと考える。

この定量方法によるデー夕の再現性については, 特に 測定を行わなかったが, 試験液 $\mathrm{A}$ 及び B による上記実 験のデータから推察すると, 再現性はキャピラリーカラ ムへのマニュアル注入の場合 $(\mathrm{RSD}=5 \sim 10 \%)$ の範囲 にあると思われる。
キャピラリーカラムによる PCB の分析における定量 化に CB（\%）法を検討した. CB（\%）法によれば PCB 標準液の組成と使用するカラムを統一することに より, クロマトグラムに普遍性が生じ, 本研究で測定し た $\mathrm{CB} \%$ 值が適用でき, 定量分析の際の標準とするこ とができる。

\section{文献}

1）JIS K 0093, 工業排水中のポリ塩素化ビフェニル (PCB) の試験方法.

2) M. Godefroot, M. Stechele, P. Sandra, M. Verzele: $H R C \& C C, \mathbf{5}, 79$ (1982).

3) J. Kraupcik, J. Mocak, A. Simova, J. Garaj: J. Chromatogr., 238, 1 (1982).

4) G. B. Copland, C. S. Gohmann: Environ. Sci. Technol., 16, 121 (1982).

5) S. P. Levine, M. T. Homsher, J. A. Sullivan: J. Chromatogr., 257, 255 (1983).

6) R. E. Lawn, S. A. Toffel: Analyst (London), 112, 53 (1987).

7) K. M. Hart, J. F. Pankow: HRC \& CC, 10, 484 (1987).

8) A. S. Lindsey, P. J. Wagstaffe: Analyst (London), 114, 553 (1989).

Method for quantitative analysis of total polychlorinated biphenyls by capillary GC. Yoshiyuki Horimoto*, Sueo Nishi, Kenji Yamaguchi and Rimiko Oguchi ${ }^{* *}$ ( ${ }^{*}$ National Chemical Laboratory for Industry, 1-1, Higashi, Tsukuba-shi, Ibaraki 305; ** Yokogawa Electric Co., Mitaka Build., 2-11-19, Nakamachi, Musashino-shi, Tokyo 180)

A method is described for the quantitative analysis of total polychlorinated biphenyls (PCBs) separated by capillary GC. Equal amount of $\mathrm{KC}-300,-400,-500$ and -600 are mixed and dissolved in hexane to prepare the reference solution $(80 \mathrm{mg} / \mathrm{l})$. The reference solution is chromatographed by capillary GC using atomic emission detector. From the chromatogram acquired by carbon emission, the abundance ratios of biphenyl groups distributed over the chromatogram are estimated. Chlorine substitute number of individual congener is also estimated by using the suggested equation. GC/MS is used for the confirmation of chlorine substitute number. Combining these data, the percent abundance of individual congener $(\mathrm{CB} \%)$ is estimated. Reliability of the method is tested by analyzing artificially mixed PCB samples, and good results are obtained.

(Received July 9, 1991)

\section{Keyword phrases}

method for analysis of total polychlorinated biphenyls; determination of individual congener. 